\section{Estudo \\ cobebate}

em Cestão

Planejamento
Revista Estudo \& Debate, Lajeado, v. 27, n. 1, 2020. ISSN 1983-036X DOI: http://dx.doi.org/10.22410/issn.1983-036X.v27ila2020.2358

\title{
COMPETITIVIDADE E DESENVOLVIMENTO DAS CIDADES: BREVES COMENTÁRIOS SOBRE A COMPETITIVIDADE, PLANEJAMENTO ESTRATÉGICO E SEUS EFEITOS NO PLANEJAMENTO URBANO
}

\author{
Fernando Alves Cantini Cardozo ${ }^{1}$, Flávio Bittencourt de Castro Júnior², \\ Claúdio José Müller ${ }^{3}$
}

\begin{abstract}
Resumo: Este trabalho visa abordar a conceituação de competitividade no âmbito de cidades como organizaçóes e como se compóe este conceito na realidade das cidades em tempos atuais. Para tanto, analisa-se como a gestão pública e a gestão do desenvolvimento urbano se relacionam na criação de ambientes propícios a um desenvolvimento sustentável. São abordados como conceitos de eficiência e inovação devem ser incorporados ao planejamento estratégico de cidades, de modo a direcioná-las ao desenvolvimento sustentável e ao posicionamento como smart cities (cidades inteligentes). Vê-se que em diversos aspectos o gerenciamento e planejamento de cidades se assemelha ao de demais organizaçóes e, consequentemente, dado um adequado posicionamento, possui potencial para otimização e busca por logística, sustentabilidade e recursos financeiros, humanos e energéticos.
\end{abstract}

Palavras-chaves: Competitividade, Cidades, Planejamento Estratégico, Cidades inteligentes.

\section{COMPETITIVENESS AND CITY DEVELOPMENT: BRIEF COMMENTS ON COMPETITIVENESS, STRATEGIC PLANNING AND THEIR EFFECTS ON URBAN PLANNING}

Abstract: This paper aims to address the concept of competitiveness within cities as organizations and how this concept is composed in the reality of cities in current times. It analyzes how public management and urban development management are related to the creation of favorable environments. towards sustainable development. They are approached as concepts of efficiency and innovation and should be incorporated into

1 Engenheiro de Minas, Mestre e Doutorando em Engenharia de Minas pela Universidade Federal do Rio Grande do Sul (UFRGS).

2 Engenheiro de Minas, Mestrando em Engenharia de Produção pela Universidade Federal do Rio Grande do Sul (UFRGS) e Especialista em Recursos Minerais na Agência Nacional de Mineração (ANM).

3 Doutor em Engenharia de Produção pela Universidade Federal do Rio Grande do Sul (UFRGS) e professor do Departamento de Engenharia de Produção da UFRGS. 
strategic city planning in order to direct them to sustainable development and positioning as smart cities. It is seen that in many respects the management and planning of cities resembles that of other organizations and consequently has potential for optimization, given an adequate positioning and search for financial, human and energy resources; logistics and sustainability.

Keywords: Competitiveness, Cities, Strategic Planning, Smart Cities.

\section{Introduçáo}

As dinâmicas da sociedade e da natureza sempre convergiram para a concorrência, princípio básico da evolução e seleção dos mais fortes, transformando-nos na sociedade e meio social que vivemos hoje. A própria concorrência do homem, entre si e com a natureza, fez com que nos desenvolvêssemos procurando arranjos mais eficientes, como a vida em sociedade e suas diferentes formas de disposição, a exemplo das cidades.

Cidades se comportam de forma semelhante a organismos biológicos, dizia o planejador urbano Abel Wolman (WOLMAN, 1965), possuindo metabolismo próprio, necessitando de insumos, e assim, disputando-os. Da mesma forma, entende-se que necessitam se relacionar com seu meio e com sistemas semelhantes (outras cidades), ou seja, coexistir, cooperar e competir. Desde o surgimento das primeiras formas de organizaçóes sociais e do encontro destas, iniciaram-se as interaçóes, seja trocando produtos e tecnologias, seja de forma belicosa, disputando recursos. Nos dias atuais, em que dispomos de níveis avançados de comunicação e de relacionamento, vemos também cenários de grandes disputas, não restritas a pessoas e organizaçôes privadas, e não restritas a países e estados. Vêse uma disputa sem precedentes entre cidades, as quais para muitos, destaca-se, é o coração da vida em sociedade (ROSE, 2019).

Fernandes (2009) ao abordar o tema desenvolvimento de cidades, observa que maioria destas, no caso brasileiro, encontra-se estagnada, restrita a uma economia local e tradicional, sem a atraçáo de investimentos; embora em diversos casos mesmo com características físicas, recursos naturais e arranjos regionais semelhantes vemos notáveis distinções dos níveis de desenvolvimento. Relativo a isto vêm as questôes: o que faz com que determinadas cidades se sobressaiam a outras? Por que em certos cenários, de ambientes ricos em recursos, não encontramos desenvolvimento? Qual a motivaçáo de termos tấo poucas cidades se sobressaindo no mundo atual?

Para tanto este trabalho visa abordar o assunto competitividade e sua relação com o desenvolvimento de cidades, bem como o uso de recursos como planejamento estratégico por cidades nos moldes aplicados no setor privado.

\section{Competitividade e Cidades}

O conceito de competitividade, como aborda Kupfer (1992), é de difícil definição, uma vez que apresenta diversas abordagens e diferentes proposiçóes de conceitos. Possas (1993) aborda de modo generalista que ser competitivo se relaciona com a possibilidade de sucesso em uma concorrência. Entretanto, a sua época, Kupfer (1992) debatia haver grande tendência na conceituaçáo de competitividade baseada em indicadores de micro e macroeconomia, com uma já clara identificaçấo de maior dificuldade de conceituar a 
competitividade em escala macroeconômica. Posteriormente, houve a incorporação de conceitos e indicadores de maior abstração, como, por exemplo, indicadores ambientais (YOUNG; LUTOSA, 2001) e de responsabilidade social (FEDOTA, 2005), entre outros, como sendo consideráveis para a composição de competitividade.

Atualmente, a conceituação de competitividade e seus indicadores variará dependendo da esfera em que se foca, havendo contornos diferentes para competitividade entre setores industriais, empresas e entre entes públicos (países, estados e municípios). De modo conceitual, é natural entendê-las de forma distinta ao se abordar empresas e setores produtivos (ex: setor vinícola e cervejeiro) e de outro lado o setor público (competição entre países, estados e municípios). Enquanto empresas visam a fixação no mercado e maximização de lucro e rentabilidade, tais objetivos são mais tênues na esfera pública. Embora um país, estado ou município, vise potencializar sua competitividade para atração de investimentos (empresas, industrias e capital) e estes se convertam em arrecadação, esta não deve ser a única objetivação da gestão pública que vise um desenvolvimento adequado e sustentável (RADOMSKY; PEÑAFIEL, 2013). A gestão pública, que almeja um desenvolvimento harmonioso, deve focar em indicadores de bem-estar e capital social (saúde, educação, distribuição de renda, e infraestrutura); entretanto, deve-se comentar que estes também são indicadores que norteiam a competitividade de um município, estado ou país.

Embora para o setor público alguns indicadores de competitividade sejam semelhantes aos do setor privado, tais como infraestrutura de transporte e logística, disponibilidade de mão de obra e capital humano, sustentabilidade socioambiental; outros, como eficiência de máquina pública, potencial de mercado, solidez fiscal (CLP, 2019), passam a compor a competitividade do setor público. Destacando que sua relevância passa a variar conforme a esfera em análise, tornam-se menos impactantes (mas não desprezíveis) quanto menor a escala (estados e municípios). Por exemplo, o potencial de mercado não apresenta mesmo impacto na competitividade entre países e entre cidades.

Especificamente para cidades, Peixoto (2000) aborda que vivem, nas últimas décadas, um "jogo concorrencial sem precedentes” pela captação de recursos (como investimentos e capital humano), onde o posicionamento competitivo irá ditar seus futuros. Neste sentido, a definição de concorrência é bem-conceituada e, em princípios das ciências econômicas (e ciências gerais), temos que a concorrência desmedida e mal gerida, não privilegia o ganho geral (a exemplo da Teoria dos Jogos). Assim, em cenários de concorrências nos campos fiscais e de incentivos diversos, a desproporcionalidade tende a prejudicar o todo, ou seja, determinada cidade atrai certo investimento, mas a sociedade perde em arrecadação (vide incentivos conferidos). A dita "guerra fiscal" tende a criar outra distorção, esta intimamente relacionada com a estabilidade fiscal (indicador de competitividade). Devido à potencial instabilidade de incentivos fiscais (os quais podem, por vezes, cessar), investimentos também são realizados com ressalvas em tais ambientes, seja por instalaçóes parciais de linhas de montagens, seja pela escolha de infraestrutura temporária, preterindo assim investimentos de longo prazo. No cenário brasileiro vemos como exemplo a zona franca de Manaus e tantos outros polos industriais, dos quais muitos padecem da incerteza decorrente da permanência industrial vinculada aos incentivos fiscais. 
Entretanto, não apenas de incentivos e isençóes se alimenta a competitividade entre municípios. Quesitos como infraestrutura de transporte (escoamento de produção) e localização (proximidade a grandes centros), conexáo com nodais de transporte (hidro-férreoaéreo-dutaria), capital humano (disponibilidade de mão de obra qualificada, proximidade com centros acadêmicos), imagem externa, disponibilidade e custo de instalação industrial, são determinantes na competitividade de uma municipalidade. Não excluem-se, também, parâmetros menos tangíveis, como a cultura local e a identificação da população e cidade, este último muito alinhado ao conhecido posicionamento de uma empresa em um mercado, consistindo na identidade que diversas cidades tendem a criar com determinados setores, adaptando sua infraestrutura e seu capital social. São exemplos, os polos de tecnologia (como Vale do Silício), metalomecânico (Caxias do Sul, São Bernardo do Campo, Detroit), centros financeiros (São Paulo, Singapura, Nova York), entre outros. Estas identificaçóes fortalecem demasiadamente a competitividade dessas cidades para atrair investimentos nas áreas em que se destacam, uma vez que potenciais investidores encontram infraestrutura, nodais e capital social adaptados, além da imagem social alinhada à da empresa, bem como demais recursos.

Dissertando sobre o tema, Kanter (1995, apud ALMEIDA, 2004), aponta que a vantagem competitiva de cidades encontra-se na otimização de "três C's": Conceitos, Competências e Cooperação. Sendo (i) Conceitos: ideias avançadas, desenhos ou novas formulaçóes para produtos ou serviços que criem valor para os consumidores; (ii) Competências: capacidade de traduzir ideias inovadoras em aplicaçóes para o mercado, produzindo-as de acordo com os melhores standarts, com as melhores práticas; (iii) Cooperação: alianças entre negócios, para alavancar competências centrais, criar mais valor acrescentado ou simplesmente permitir o acesso a horizontes mais vastos e aproveitar a oportunidade da globalização das economias (ALMEIDA, 2004). Princípios bem semelhantes são apontados por Rose (2019) como sendo fundamentais para "centros urbanos alçarem voos rumo a prosperidade".

Rose (2019), embora trate do desenvolvimento das cidades em sentido amplo, aborda de forma sistemática como o desenvolvimento de determinadas cidades e centros urbanos deu-se de modo eficiente em função de fatores como: alinhamento de cultura, integração com seu meio físico, infraestrutura de transporte e escoamento de produção, gestão adequada, inovação tecnológica, fortalecimento e valorização do capital humano, adequado sistema fiscal. Nota-se que estes nada mais são que indicadores atuais de competitividade, reforçando assim a importância desta para o desenvolvimento das cidades e seus sistemas. O Autor (ROSE, 2019) é enfático em determinar estes fatores como fundamentais para o sucesso de cidades, entretanto, também aborda que, tão fundamental quanto estes, é a integração e cooperação, em detrimento da competição desordenada, de modo que cidades (assim como empresas), devam focar em suas potencialidades e criar laços e trocas com outras diversas, cooperando para o crescimento mútuo. Na definição de Winckler (2011), coopetição representa o comportamento de cooperação competitiva entre empresas, ou seja, elas cooperam para atingir determinado objetivo e competem na hora de dividir os ganhos. Assim, tal autor expóe que esses jogadores formam uma Rede de Valores, que representa todos os jogadores e as interdependências existentes entre eles. Essa definição, ao 
percebermos o contexto das cidades, se torna contundente, uma vez que as cidades muitas vezes são interdependentes quanto mais próximas estiverem. Essa escala diminui com o distanciamento, não só geográfico, mas de nível (esfera estadual, federal, continental, etc.).

\section{Planejamento Urbano, inovaçáo, eficiência e sua relação com a competitividade}

Smart Cities (Cidades Inteligentes) são cidades que, entre outras coisas, apresentam eficiência energética, otimizando a relação de produtos gerados em função do custo para produzi-los, em se tratando de energia, bens, informaçóes, entre outros. Abel Wollman (WOLLMAN, 1965), então engenheiro da cidade de Nova York, foi um dos primeiros profissionais a entender e a tratar de uma cidade como um organismo, que necessita de insumos (alimento) e apresenta saídas (resíduos), sendo que para o sucesso e desenvolvimento do organismo cidade, esta relação energética deve ser otimizada. Lambert et al. (2014) abordam a existência de um indicador de eficiência energética, o EROI (Energy Return on Investiment), retorno sobre investimento energético, o qual pode ser interpretado de diversas formas, como na quantidade de água potável que é gasta para produzir determinada quantidade de água potável, ou quantos barris de petróleo são necessários para produzir um barril (onde se espera que custo de produção de um barril seja inferior a um). Tal índice é abordado como fator determinante para o desenvolvimento de sociedades ao longo da história, enquadrando-se nos campos que hoje classificamos como eficiência, sustentabilidade e inovação. Em outras palavras, cidades tornam-se mais competitivas, aptas ao desenvolvimento, conforme suas relaçôes de EROI são otimizadas (ROSE, 2019). Analogamente, há a valorização da imagem de sistemas e produtos que levam tal princípio de eficiência em seu conceito e desenvolvimento, como no caso de certificaçóes internacionais como a LEED (Leadership in Energy and Environmental Design), onde sistemas e produtos que incorporem estes princípios agregam um diferencial altamente atrativo (sobretudo em termos de imagem as empresas que consomem estes produtos). Tal atrativo não é restrito a imagem, mas abrange fatores como a eficiência e inovação. Torna-se impensável não conceber o planejamento e gestão estratégica de cidades pautados em tais princípios, dando molde à chamada economia circular (Figura 1).

Rose (2019) aborda a adoção da economia circular como um dos pilares para o desenvolvimento e prosperidade de uma cidade, onde uma cidade migra de sistemas industriais ditos lineares para sistemas cíclicos e regenerativos. Esse redirecionamento ocorre a medida em que são estimulados os reaproveitamentos e reúso de resíduos, assim como a conexão e consumo colaborativo dos atores locais (indústrias e consumidores), dependendo assim, de boa governança, infraestrutura inteligente e inovação. 
Figura 1- Economia circular de sistema urbano

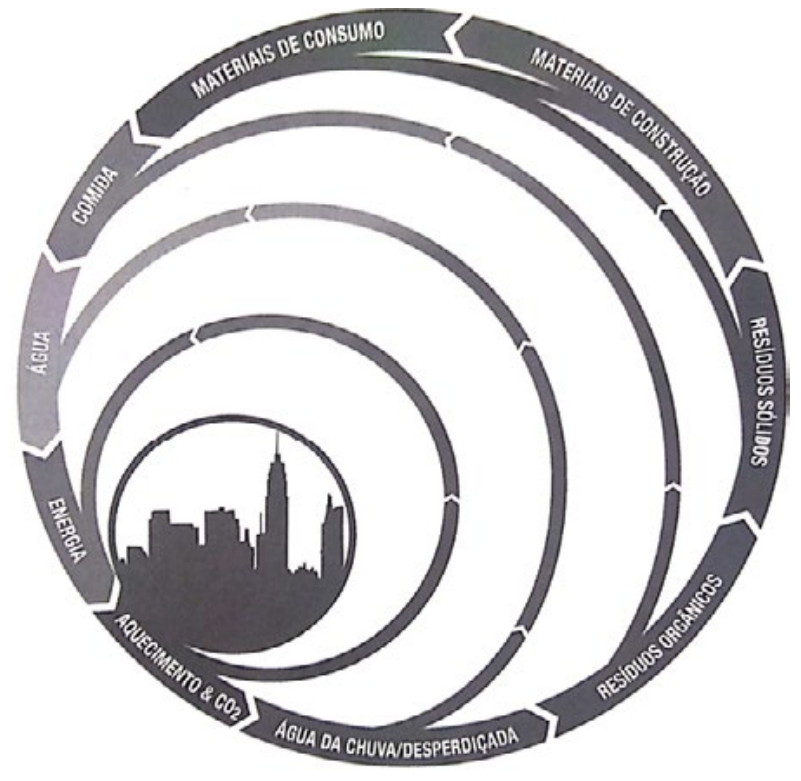

Fonte: Rose (2019)

Em termos de planejamento, facilmente identifica-se, na maioria das cidades do Mundo, sobretudo as brasileiras, potenciais de otimização de recursos, sobretudo no uso de espaço urbano. Um exemplo claro de oportunidade de aproveitamento é o investimento em espaços subterrâneos e na verticalizaçáo planejada, os quais concentram serviços e agilizam deslocamentos, diminuindo suas perdas com a ineficiência. Grandes centros mundiais, como Nova York, vem a certo tempo investindo e fomentando alternativas como a agricultura urbana, prática que aproveita espaços ociosos como terrenos baldios e coberturas de edificaçôes. Esta prática representa não só uma economia com as longas distâncias percorridas com alimentos (eficiência logística), mas também uma adiçâo de inovação e sustentabilidade à imagem das cidades. Tais quesitos são valorizados por empresas e sociedade, sendo um atrativo extra para pessoas, em geral, de boa formação e que se identificam com os temas de inovação e sustentabilidade. Essas práticas, bem como o uso de fachadas verdes e reservaçáo de águas pluviais, podem ser facilmente fomentadas pelo poder público através de incentivos e bonificações em impostos. Entretanto, maneira mais direta é o exemplo que a gestão pública pode dar a cidade, adotando práticas sustentáveis em suas instituiçóes e edificaçóes. Diversas empresas, por exemplo, estimulam a prática de compostagem e hortas comunitárias em seus próprios prédios; bonificam funcionários que optam pelo uso de bicicleta e transportes alternativos ao invés do carro. Outra tendência, implementada em cidades como Estocolmo, Londres, Singapura e, mais recentemente, Nova York, é a utilização de pedágios urbanos, reposicionando o uso de uma cidade para sua população, reduzindo o trânsito de veículos individuais e direcionando recursos para transportes coletivos, na intenção de maximizar sua eficiência. 
Açóes desse gênero podem ser olhadas em sentido mais amplo, tanto para cidades quanto para empresas. A postura de apoio a práticas sustentáveis náo deve ser vista apenas como agregaçáo de valor à imagem da organização, mas sobretudo como forma de maximização de eficiência energética (redução de custos) e da saúde de sua população (e/ou funcionários), reduzindo perdas (com o que se chama custo de oportunidade) em tratamentos de saúde e mesmo com o tempo no tráfego das grandes cidades, sendo inúmeros os estudos que pontuam as perdas econômicas decorrentes de tais externalidades.

\section{Planejamento Estratégico para cidades como organizaçóes}

Do modo como as cidades se relacionam entre si, trabalham cooperativamente e competem por recursos, é natural que sejam caracterizadas como organizaçóes e, assim, se componham apresentando objetivos, finalidades, posicionamentos e estrutura organizacional. Desde o início da estruturação das cidades os papéis hierárquicos se desenvolveram, cabendo aos mais hábeis, mais experientes e preparados para a atividade, os postos de maior nível, semelhante ao que ocorre na maioria das organizaçóes privadas. Distinguem-se, entretanto, do desenvolvimento das organizaçóes privadas, no que diz respeito a evolução da gestáo pela excelência e adição de ferramentas e conceitos de planejamento estratégico, de valores de organização, de desenvolvimento institucional, de benchmarking, de lean manufacturing, de brainstorm, entre diversas outras ferramentas. Cidades, como organização, precisam acompanhar este desenvolvimento.

Condutas simples, como a observação e cópia de ações exitosas de outras empresas e cidades, são geralmente negligenciadas no desenvolvimento de um planejamento estratégico em grande parte das cidades brasileiras. Pode-se dizer que a simples identificação de uma cidade como uma organização, com missão, visão e valores, em muito contribuiria para nortear seu desenvolvimento e colocá-la em uma posição de vantagem na competição com outras. Logicamente, cidades são organizaçôes sem fins lucrativos, mas não por isso são passiveis de negar as ferramentas de gestão e de otimização utilizadas na maximização de empresas que buscam o lucro. Possivelmente, ao adotarem o roteiro utilizado por empresas quanto a sua identificação de negócio, planejamento estratégico, benchmarking, gestão horizontalizada, Lean Manufacturing, valorização de seus talentos, entre outras açôes, abrirse-ia espaço para cidades mais coerentes, coesas, resilientes e competitivas. Tal pensamento tem como maior vitrine o sucesso da cidade de Barcelona e de cidades que se valeram das mesmas açóes e medidas de planejamento estratégicas, diversas das quais sobre consultoria de planejadores catalães, como Medelín e, recentemente, Porto Alegre.

Embora autores como Vainer (2000) e Lima Junior (2003) coloquem que cidades não devam ser tratadas como empresas e que tais práticas afastem seus objetivos sociais, dando lugar a um posicionamento competitivo, cabe ponderar que as ferramentas de gestão podem ser aplicadas, não apenas com o enfoque de geração de lucro, mas para a definiçáo e o alcance dos próprios objetivos da cidade no que tange aos objetivos sociais. Os gestores, com tais definiçóes, conseguiriam focar seus esforços de maneira inteligente. Conquanto, como no competitivo mundo dos negócios, a idealização da maximização mútua de ganhos seja algo complexo, tal definição se enquadra para cidades. Analisando a bibliografia 
disponível quanto ao crescimento econômico e urbano de cidades e a inovação, é possível verificar uma quase onipresença do termo competitividade.

Outro ponto que reforça a necessidade de entendimento de uma cidade como uma organização e a necessidade de seu planejamento estratégico e posicionamento competitivo, sobretudo na realidade brasileira, é a visão adotada por diversas cidades internacionais, que buscam posicionamento como smart cities (cidades inteligentes) como uma forma de se tornarem cidades mais eficientes, agradáveis e competitivas. Entretanto, referente ao conceito de planejamento estratégico a ser adotado por cidades, Lima Junior (2003), pondera que este deve estar aderido as particularidades de cada cidade, seu espaço físico e sua vida social. De outra forma, adotando-se modelos preestabelecidos, deixa de ser uma ferramenta construtiva.

\section{Smart Cities e competitividade}

O conceito de Smart Cities (Cidades Inteligentes), embora não seja propriamente novo, tornou-se aplicável devido aos recentes desenvolvimentos tecnológicos que possibilizaram transmissóes e processamentos de informaçóes em tempo real. Caragliu, Del Bo e Njikamp (2011) comentam que caracterizar uma smart city é algo complexo e normalmente associado à inovação e informação. Em suas conclusóes (baseadas em análises de dados), os autores avaliam ser positiva a relação entre riqueza urbana e fatores como profissionais criativos (indicador de inovação), mobilidade urbana e informatização da gestão pública. Batty et al. (2012) citam que o conceito de cidade inteligente surgiu durante a última década como uma fusão de ideias sobre como as tecnologias de informação e comunicação podem melhorar o funcionamento das cidades, aumentando a sua eficiência, melhorando a sua competitividade e contribuindo para um desenvolvimento sustentável. A essência da ideia gira em torno da necessidade de coordenar e integrar tecnologias que até agora foram desenvolvidas separadamente, mas têm sinergias claras em sua operação e precisam ser acopladas para que muitas novas oportunidades de melhoria da qualidade de vida possam ser realizadas.

Neste contexto, autores como Weiss, Bernardes e Consoni (2015) dizem que a mais recente perspectiva tecnológica de cidades inteligentes é a implementação da Internet das Coisas (Figura 2), conceito bem conhecido na chamada indústria 4.0 (LU, 2017). Zanella et al. (2014) dissertam sobre como a Internet das Coisas transforma uma cidade e a torna mais inteligente a medida que permite que seus gestores e usuários tenham um maior conhecimento quanto a sua realidade, incluindo áreas como saúde, infraestrutura, resíduos, iluminação pública, estacionamentos, qualidade do ar, entre outras. A disponibilidade, processamento e análise de informaçóes de uma cidade em tempo real, contribuem em muito para seu desenvolvimento e economia, à medida que possibilitam diminuição de custos, ao maximizarem investimento, aplicando-os onde são realmente necessários; ao aumentarem a eficiência dos transportes, reduzindo ociosidade; ao maximizarem receitas; ao fornecerem bases adequadas para cobranças mais justas de impostos e taxas. 
Figura 2 - Da cidade digital a cidade inteligente

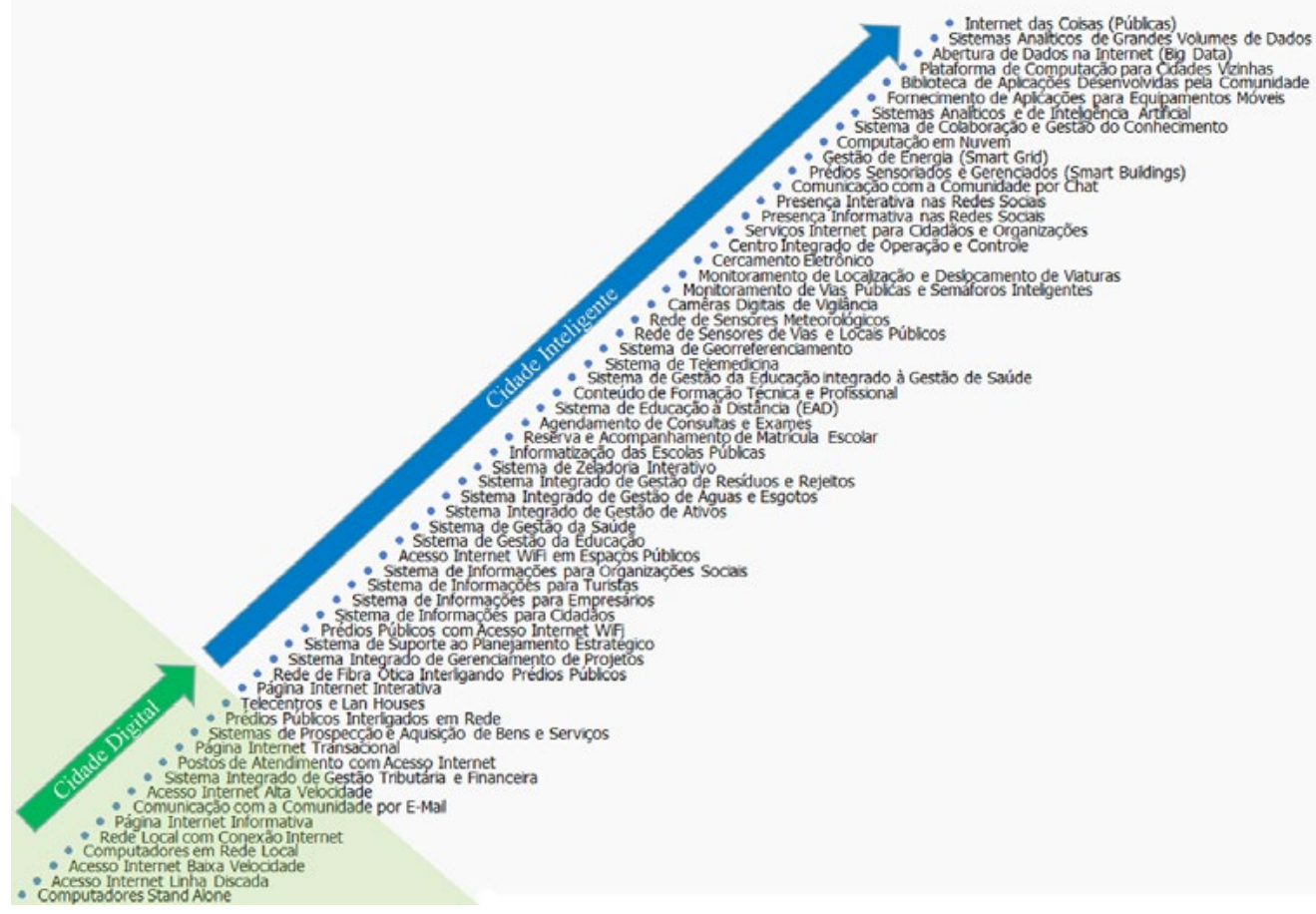

Fonte: Weiss, Bernardes e Consoni (2014)

O conceito de smart city, de maneira geral, engloba todos os conceitos que tornam uma cidade competitiva: sustentabilidade, inovação, capital humano, governança, mobilidade; e os entrelaça com a conectividade da informação. Quanto ao planejamento estratégico de cidades, podemos destacar um duplo posicionamento, uma vez que entende-se que ser uma smart city, pode fazer parte do planejamento estratégico de uma cidade, mas para ser uma smart city, uma cidade deve ter um planejamento estratégico. Vemos então uma relação de dependência entre o planejamento estratégico e esta conceituação. É importante destacar, entretanto, que assim como para muitas empresas, almejar um desenvolvimento limitado (ou nulo), ou mesmo uma retração de seu tamanho, pode fazer parte do planejamento estratégico de uma cidade. Não adentrar na era digital, da comunicação e informação em tempo real, pode ser uma estratégia adotada.

Em termos de desafio no desenvolvimento de cidades e em sua progressão para o alcance do status de smart cities, Eleutheriou et al. (2015) citam a Tragédia dos Comuns (trabalho do prêmio Nobel de economia Elinor Ostrom), onde temos um cenário pessimista para o gerenciamento de bens comuns (ou públicos). Para esta situação, os autores sugerem o uso de metodologias de Design Thinking, recentes até mesmo no mundo dos negócios, sobretudo na realidade brasileira.

Landry (2006) traz a ideia de que as cidades são o núcleo do desenvolvimento econômico, e isso significa que, para governar a cidade, os políticos e administradores 
não devem procurar resolver todos os problemas, mas fortalecer a capacidade dos sistemas urbanos de enfrentar uma grande variedade de problemas e produzir uma ampla gama de soluçóes voltadas aos valores públicos. Batty (2012) enfatiza que as cidades estáo se tornando inteligentes não apenas em termos de como automatizar as funçóes de rotina que atendem pessoas individuais, edifícios e sistemas de tráfego, mas de modo a monitorar, entender, analisar e planejar a cidade para melhorar a eficiência, a equidade e a qualidade de vida de seus cidadãos em tempo real. Há amplo consenso de que as políticas governamentais têm um papel crítico a desempenhar na promoção de cidades inteligentes (YIGITCANLAR et al., 2008) e isso se encaixa bem na perspectiva da gestão pública, que destaca que solucionar problemas sociais não é apenas uma questão de desenvolver boas políticas, mas especialmente uma questáo gerencial de organizar uma forte colaboraçáo entre o governo e outras partes interessadas (TORFING et al., 2012).

A busca por uma cidade inteligente passa por fomentar em seus próprios cidadãos soluçóes que podem ser direcionadas, uma vez que a cidade possui em seu escopo ferramentas que permitem perceber qual direção se quer que a cidade siga. Assim, mais do que a gerência dos problemas da cidade em si, a formulação de políticas públicas se torna essencial para o desenvolvimento de uma smart city.

Conforme expóe Meijer et al. (2016), a questão da sinergia sócio-tecno está sendo ampliada do nível da organização - ou da cadeia de organizaçóes - para o nível do sistema urbano, fazendo com que conceitos e teorias existentes possam ser usados como base para estudar, na condição de que sejam revisados para torná-los adequados ao estudo de interaçóes urbanas.

Meijer et al. (2016), ao realizarem estudos bibliográficos sobre a significação de smart cities, classificaram três tipos diferentes de definições típicas ideais: cidades inteligentes como cidades usando tecnologias inteligentes (foco tecnológico); cidades inteligentes como cidades com pessoas inteligentes (foco em recursos humanos); cidades inteligentes como cidades com colaboração inteligente (foco de governança). Apesar dessa diferenciação, a tecnologia sempre se constitui como ponto de partida para repensar todas as demais questóes. Contudo, o conceito de cidade inteligente baseia-se principalmente nas características dos habitantes inteligentes, em termos do seu grau educacional (pessoas inteligentes), e este nível de educação é visto como um dos principais impulsionadores do crescimento urbano (LOMBARDI et al., 2012; SHAPIRO, 2006). Na terceira definição, a ideia de colaboração é mais central para esta abordagem e os autores se concentram no desenvolvimento de interaçóes produtivas entre redes de atores urbanos (KOURTIT et al., 2012; YIGITCANLAR et al., 2008). Combinaçóes desses três elementos - tecnologia inteligente, pessoas inteligentes e colaboração inteligente - são feitas em vários trabalhos. Hollands (2008) enfatiza que cidades inteligentes requerem não apenas tecnologias de informação sofisticadas, mas também a contribuição de vários grupos de pessoas.

É importante perceber que as definições anteriores não se centram somente na tomada de decisóes inteligentes por parte do governo, mas da cidade como um todo, ao ponto de Meijer et al. (2016) terem identificado quatro conceituaçóes típicas ideais de governança de cidade inteligente: (i) governo de uma cidade inteligente, (ii) tomada de decisão inteligente, (iii) administração inteligente e (iv) colaboração urbana inteligente. Os autores (MEIJER et 
al., 2016) concluem que, na visão geral dos artigos pesquisados por eles, mostra-se que há uma crença dominante de que a transformaçáo da governança é desejável e necessária para tornar as cidades inteligentes. Pode-se questionar se isso é sempre necessário, e um pequeno grupo de publicaçôes realmente destaca que tornar uma cidade mais inteligente é encontrar maneiras melhores de executar as tarefas básicas do governo. $\mathrm{Na}$ compreensão dos autores (MEIJER et al., 2016), é importante perceber que a governança da cidade inteligente pode ser classificada em uma escala desde a conservação institucional (governança tradicional de uma cidade inteligente) até a transformação institucional (governança urbana inteligente).

\section{Consideraçóes Finais}

Este trabalho visou trazer ao debate o tema competitividade em cidades, e como estas em certos momentos devem(riam) se posicionar como empresas e organizaçóes, destacando-se também aspectos que diferenciam as cidades de empresas em termos de desenvolvimento e competição. Alguns aspectos se mostraram marcantes, principalmente o fato do tema "competitividade entre cidades" ser amplamente abordado por diversos autores como um aspecto que deve ser observado e buscado para o caso de cidades que almejam desenvolvimento e posicionamento em patamares superiores. Ao mesmo tempo que aspectos, como objetivos sociais e demais políticas públicas, tornam diferenciáveis a competitividade e aplicação de planejamento estratégico em empresas e organizaçóes privadas em comparaçáo a cidades. Deste modo vemos a impossibilidade da ocorrência de um modelo único replicável de para planejamento estratégico.

Vê-se que, assim como empresas, cidades se tornam competitivas quando apresentam diferenciais positivos em termos logísticos, tecnológicos, de capital humano, eficiência de gestâo e fatores como preocupação ambiental e social; até mesmo no posicionamento de "sua marca", na imagem que uma cidade deseja passar para sua população e para o resto do mundo. Há grande consenso em todos estes aspectos e em como estes geram vantagens competitivas a uma cidade, sobre outras, na atração de investimentos e em capital humano. Entretanto, o aspecto cooperação (entre cidades), onde cidades cooperam entre si no intuito de maximizar ganhos, gerando-se polos produtores (industrial, rural, tecnológico, em saúde, entre outros), é algo não tão comum, considerando a falta de referências ao tema. Temos ainda que as revoluçôes tecnológicas, que levaram a indústria ao status de Indústria 4.0, também pesam na competitividade de cidades; conectividade, fluxo e processamento de informações em tempo real são importantes ferramentas para o desenvolvimento urbano. Nestes aspectos, vê-se uma lacuna que ajuda a compreender porque vemos tão poucas cidades se sobressaindo ou mesmo posicionadas em um alto patamar de competitividade.

Para além disso, $\mathrm{o}$ artigo aborda como olhar para a cidade de forma a promover não apenas uma gestão eficiente do governo, mas de tornar a cidade inteligente, ao se olhar para os cidadãos que a compóe, não apenas para os recursos tecnológicos, bem como para os diversos atores dela, uma vez que estes podem trazer soluções. Pela visão deste artigo, tal processo necessita de aporte de gestáo a fim de direcionar os esforços de todos estes atores envolvidos. Tal planejamento estratégico necessitará considerar que os processos para tornar a cidade mais inteligente passarão a focar também em como tornar seus recursos humanos mais inteligentes, a ponto de contribuírem na construçáo da cidade. 


\section{Referencias}

ALMEIDA, Clarinda da Costa. O marketing das cidades. Gestáo e Desenvolvimento, v. 12, p. 9-45, 2004.

BATTY, Michael et al. Smart cities of the future. The European Physical Journal Special Topics, v. 214, n. 1, p. 481-518, 2012.

CARAGLIU, Andrea; DEL BO, Chiara; NIJKAMP, Peter. Smart cities in Europe. Journal of urban technology, v. 18, n. 2, p. 65-82, 2011.

CLP, Ranking de competitividade dos estados. http://www.rankingdecompetitividade. org. br/destaque/entenda-o-ranking-de-competitividade-dos-estados-. Acessado em: 12 de Março de 2019.

ELEUTHERIOU, Vanessa et al. O Design Thinking como ferramenta colaborativa para o desenvolvimento de cidades humanas e inteligentes em prol do bem comum. Blucher Design Proceedings, v. 2, n. 3, p. 51-56, 2015.

FEDATO, Maria Cristina Lopes. Responsabilidade social corporativa: benefício social ou vantagem competitiva?: um estudo das estratégias de atuação social empresarial e sua avaliação de resultados. Tese de Doutorado. Universidade de São Paulo. 2005.

FERNANDES, Ana Cristina. Conhecimento, desenvolvimento regional e as cidades brasileiras. In: BITOUN, J. MIRANDA, L. Desenvolvimento e Cidades no Brasil. Contribuiçóes para o Debate sobre as Políticas Territoriais. Recife: FASE: Observatório das Metrópoles, 2009.

HOLLANDS, Robert G. Will the real smart city please stand up? Intelligent, progressive or entrepreneurial?. City, v. 12, n. 3, p. 303-320, 2008.

KOURTIT, Karima; NIJKAMP, Peter; ARRIBAS, Daniel. Smart cities in perspective-a comparative European study by means of self-organizing maps. Innovation: The European journal of social science research, v. 25, n. 2, p. 229-246, 2012.

KUPFER, David. Padróes de concorrência e competitividade. Encontro Nacional da ANPEC, v. 20, p. 1, 1992.

LAMBERT, Jessica G. et al. Energy, EROI and quality of life. Energy Policy, v. 64, p. 153-167, 2014.

LANDRY C. The Art of City Making. London: Routledge. 2006.

LIMA JUNIOR, P. de N. Uma estratégia chamada “planejamento estratégico": deslocamentos espaciais e atribuiçóes de sentido na teoria do planejamento urbano. Tese de Doutorado. Universidade Federal do Rio de Janeiro, Rio de Janeiro. 2003. 
LOMBARDI, Patrizia et al. Modelling the smart city performance. Innovation: The European Journal of Social Science Research, v. 25, n. 2, p. 137-149, 2012.

LU, Yang. Industry 4.0: A survey on technologies, applications and open research issues. Journal of Industrial Information Integration, v. 6, p. 1-10, 2017.

MEIJER, Albert; BOLÍVAR, Manuel Pedro Rodríguez. Governing the smart city: a review of the literature on smart urban governance. International Review of Administrative Sciences, v. 82, n. 2, p. 392-408, 2016.

POSSAS, Maria Silvia. Concorrência e competitividade: notas sobre estratégia e dinâmica seletiva na economia capitalista. Tese de Doutorado. Universidade Estadual de Campinas. 1993.

RADOMSKY, Guilherme; PENÁFIEL, Adriana. Desenvolvimento e sustentabilidade. Curitiba: InterSaberes, 2013.

ROSE, Jonathan F.P. A Cidade em Harmonia: O que a Ciência Moderna, Civilizaçóes Antigas e a Natureza nos Ensinam Sobre o Futuro da Vida Urbana. Porto Alegre: Bookman, 2019.

SHAPIRO, Jesse M. Smart cities: quality of life, productivity, and the growth effects of human capital. The review of economics and statistics, v. 88, n. 2, p. 324-335, 2006.

TORFING, Jacob et al. Interactive governance: Advancing the paradigm. Oxford University Press on demand, 2012.

VAINER, Carlos. Pátria, empresa e mercadoria: notas sobre a estratégia discursiva do Planejamento Estratégico Urbano. In: ARANTES, O. et al. A cidade do pensamento único: desmanchando consensos, v. 3, p. 75-103, 2000.

WOLMAN, Abel. The metabolism of cities. Scientific American, v. 213, n. 3, p. 178$193,1965$.

WEISS, Marcos Cesar; BERNARDES, Roberto Carlos; CONSONI, Flavia Luciane. Cidades inteligentes como nova prática para o gerenciamento dos serviços e infraestruturas urbanos: a experiência da cidade de Porto Alegre. Revista Brasileira de Gestáo Urbana, v. 7, n. 3, p. 310-324, 2015.

WINCKLER, Natália Carrão, MOLINARI, Gisele Trindade. Competição, colaboração, cooperação e coopetição: revendo os conceitos em estratégias interorganizacionais. Revista ADMpg, v. 4, n. 1, p. 1-12, 2011.

YIGITCANLAR, Tan; VELIBEYOGLU, Koray; MARTINEZ-FERNANDEZ, Cristina. Rising knowledge cities: the role of urban knowledge precincts. Journal of knowledge management, v. 12 , n. 5 , p. $8-20,2008$. 
YOUNG, Carlos Eduardo Frickmann, LUSTOSA, Maria Cecília Junqueira.

Meio ambiente e competitividade na indústria brasileira. Revista de Economia

Contemporânea, v. 5, n. 1, p. 231-259, 2001.

ZANELLA, Andrea et al. Internet of things for smart cities. IEEE Internet of Things journal, v. 1, n. 1, p. 22-32, 2014. 